\title{
The Role of Antenatal Education in Promoting Maternal and Family Health Literacy BACKGROUND
}

Health literacy is acknowledged as a critical determinant of health (World Health Organization, 2016), particularly for birthing women and their families (Renkert \& Nutbeam, 2001). Nutbeam defines health literacy as "[t]he personal, cognitive and social skills which determine the ability of individuals to gain access to, understand, and use information to promote and maintain good health" (Nutbeam, 2000). He outlines three levels of health literacy: functional, interactive, and critical. Functional health literacy provides the foundation that enables people to gather information related to their health. Interactive health literacy is a second level wherein people reflect on how they can adapt information to new situations as a basis for health-related decision-making. Critical health literacy is a higher order cognitive ability in which individuals are able to participate in both private and public dialogues about health in the context of society and culture as well as the health service environment (Nutbeam, 2000).

The goal of promoting health literacy in the context of Antenatal Education (ANE) is to empower expectant parents with knowledge, skills, and confidence to know where and how to find additional information, and to develop their ability to analyze that information critically (Nutbeam, 2000). Studies have found that people with skills in health literacy take a more active role with respect to their health care (Berkman, 2011; Birimani et al., 2018; Nijman et al., 2014), which is an important health promotion goal across the continuum from birth to parenting (Nutbeam, 2000).

Contemporary ANE has attracted considerable attention from professional services, web-based resources, and social media. In Australia, ANE is currently delivered within antenatal care services, as a formal standalone educational experience or as a combination of group and conventional care for women and their partner or support person (Homer, Ryan, 
Leap, Foureur, \& Teate, 2012). The background and qualifications of the educators varies, as does the structure and format of the programs. Despite ANE being an expected part of pregnancy care, there has been limited investigation into the structures and processes of these programs. This study considers contemporary ANE in Australian-based settings; their development and delivery, and women's experiences of ANE in relation to their information needs. The two primary research questions were to explore:

What key factors influence pedagogy and practice of ANE in Australian contexts?

To what extent does current antenatal education provide meaningful and effective learning experiences that would foster health literacy from the perspectives of both the educators and the consumers?

\section{METHODS}

\section{Study Design}

The study used Interpretive Description to describe and interpret the actual experiences of antenatal educators and class participants. This qualitative, clinician-driven methodology is designed to address practice issues and inductively generate knowledge that is applicable to the healthcare context (Thorne, 2016) as well as to birthing women and their families.

\section{Recruitment and Sampling}

A convenience sample of 18 women was recruited; eight participants attending ANE for their first or subsequent pregnancy, and ten current providers of ANE classes. All responded to a request to contact the researcher via email or telephone to organize an interview. Participants received a detailed project information sheet and provided signed consent. All participants were assigned a pseudonym to maintain confidentiality. Conduct of this study was approved by the university ethics committee (USC S/13/506).

\section{Data Collection}


A semi-structured interview guide for both educators and attendees was developed to ensure consistency across face-to-face or phone interviews of 45-90 minutes' duration (See Table 1). All interviews were audio recorded and transcribed. Eight educators agreed to participate in a follow up interview to clarify points and discuss initial interpretation and findings. This was not offered to class participants to preclude any pressure during their birth and postpartum period.

\section{Insert Table 1 here}

\section{Data Analysis}

An inductive approach to thematic analysis constructed meanings from participants' experiences (Thorne, 2016). Transcripts generated in preparation for analysis were subsequently reviewed by the authors. NVivo was used to assist with identifying, labelling and comparing data within and across sources (Bergin, 2010). The analysis included constant comparison of all transcripts, noting any similarities or differences between them (Thorne, 2016). Inductive interpretation was framed by using Morse's (1994) four cognitive processes of analysis. These processes comprised examination and comprehension of the elements of the data; synthesis by testing and challenging initial assumptions and findings to inform further propositions; representation in themes, and recontextualization to produce the conceptual description.

\section{RESULTS}

Five themes and nine associated subthemes were identified, presented in Table 2 with exemplars from the participants, elaborated below.

\section{Insert Table 2 here}

\section{Theme 1: Balancing Provider Influences with Participant Expectations}




\section{Ensuring Adequate Information to Meet Participants' Needs}

Educator responses suggested that they were under pressure from managers with the need to cover and document specific information, verifying that the information was discussed with class participants. This expectation often meant institutional requirements were given priority over consumers' learning needs.

"there is pressure to cover the discussion topics and the information at each point without getting off track and then ...you've gotta sign that you've passed that information onto the women." (Clara educator)

The institutional expectations often precluded being responsive to participants' concerns in a timely manner. Class participants' preferences for specific topics were often ignored, and some irrelevant content included. Fern, who was approximately 28 weeks' gestation at the time of her first class, commented specifically about the topic of conception: "In the first hospital class I thought to myself my goodness, if you don't know how babies are conceived by now, you're really in trouble." (Fern, participant).

Ella would have liked more information about tandem breastfeeding, a topic specific to her situation: "I was still breastfeeding (daughter) when I fell pregnant with him and so I was a bit nervous, a bit overwhelmed. They just ticked off that they'd done it (taught breastfeeding), but they didn't talk to me about any of it. I was a bit disappointed because I...especially wanted information, because I was willing to tandem feed, if I needed to." (Ella, participant).

\section{Meeting the Expectations of Managers/Supervisors}

Several antenatal educators and class participants commented on the didactic methods used as a one-way, teacher-focused style rather than being responsive to learner needs. Half the antenatal educators used a structured presentation, most using PowerPoint to simply transfer 
information: "So that's a generic PowerPoint... it's a stand-alone session 1, 2, 3, 4 and you can just pick it up and teach it from that session" (Dawn, educator)

Clara's comments reflect her preference for more facilitative teaching: "I think that would be really lovely to have a lot more group facilitated antenatal care rather than the structured and didactic...looking at all of the feedback and the research done around the facilitated group care...the women's experiences when they have been in that model have been overwhelmingly positive." (Clara, educator)

\section{Theme 2: Accommodating Learning Styles and Preferences}

\section{Adjusting teaching Strategies}

Most antenatal educators used objects and images to demonstrate how the baby and placenta are born, passing the objects around to touch, use and discuss them to clarify understanding. These stimulated further questions and engagement, with class participants commenting that they learned through touching, feeling and experiencing the activity hands-on. Active engagement in the activities helped learners become absorbed in the material, which prompted group discussions: "It keeps the moms a bit more focused about they're actually going to have a beautiful baby while there are all the discomfort of pregnancy and concerns, they might have about their growing babies" (Clara, educator)

Claire believed that having the tactile objects was especially important for the men, observing: "You could see a lot of the dads just zoning out, so it was good for them to be given something to play with and look at and wake up again." (Claire, participant).

Theoretically, all antenatal educators were working toward the goal of health literacy, but those who used a facilitative active learning style enabled the participants to contribute to the class discussion in a meaningful way. They felt able to lead the class in discussions about aspects of pregnancy, childbirth or parenting issues of interest on that day. Within this 
approach all group members could observe that others were also experiencing the same sort of issues, which normalized their pregnancy experiences.

Active involvement also helped inform the educators what the participants wanted to learn about. Joy encouraged the women to ask questions of the health care providers where they had booked their birth: "Well, I emphasize women actually being actively involved in their care, so that they actually ask questions and engage with health care providers about what is being offered to them and how their health is progressing and all of those things." (Joy, educator)

\section{Recognizing Alternative Sources of Information}

The women did not rely solely on classes for antenatal information, as many came to classes prepared, having sourced considerable information elsewhere to prepare for labor, birth and parenting. Some were cautious about information available on the internet, concerned about the overwhelming volume of information there. Gina and Fern, both first time mothers, preferred to read books about birth and parenting: "I think also there is so much information out there on the internet and perhaps with the first baby you don't know what you're looking for so it's good to go to classes." (Fern, participant)

and

"I'd prefer to read a book about things as opposed to just going online and trying to find information. Because there's too much information... it's overwhelming." (Gina, participant)

In contrast, Amy a mother of three, found that the internet and internet-based support groups were very helpful in addressing her specific questions: "So, I get a lot of incidental education... the articles that pop up and I see, so I will read and go, oh, I didn't have any idea about that, that's really interesting." (Amy, participant). In many cases women provided examples of information they had researched online, through reading and discussions with 
friends or online acquaintances. Importantly, they seemed well prepared, accessing information from a wide range of sources to meet individual needs.

\section{Theme 3: Influence of the Environment on Pedagogy and Practice}

\section{Organization of the Learning Space}

Some antenatal educators provided classes in the woman's home while others were in the local school library, the local tavern, a community based multipurpose room, or in the healthcare facility. All attempted to create a positive learning environment, enabling class participants to feel comfortable, safe and engaged, with attention to the layout of the room, seating arrangements and any institutional restrictions: "We set (the room) up when we do the group antenatal care... everyone in a circle... it's important to have that circle because it gives women that bond straight away and everyone can see each other, no one is in a powerful position." (Anna, educator)

Clara used a combination of a circle layout for the hospital facilitated classes, but she also felt the need to stand at the front for instruction to add to her credibility: "The majority of it was didactic teaching where I was at the front standing up, the moms and dads were sitting in a sort of a circular motion, but I was always at a different level to them and talking about the main phases throughout the antenatal period." (Clara, educator)

One of the expectant mothers highlighted the difference that the seating arrangements made: "The first one we were put like theatre style, so all facing the front, with your couples. Then, on the last one, we were actually in a circle, which was nicer I thought because...we'd built a relationship with each other and things like that, so it was more talking to the group rather than just listening to the presenter, which was good." (Bella, participant). The theatre like style prohibited much interaction amongst the participants, potentially establishing a 
power dynamic for the educators "so they're more like talking down to you." (Gina, participant)

\section{Influence of Class Size and Number of Participants}

The educators explained that large class sizes could inhibit learning and reduce the interactive nature of the group. However, Joy, a doula and private practice antenatal educator, ran her classes as a business, so smaller class numbers was not financially viable.

Irene facilitated male partner classes at a local tavern where the men had a lecture style presentation enjoying an informal meal together where the class discussion continued. "The nights where we have the really little numbers, where it's not viable for me to be doing it, are the best. Eight to 10, it's perfect, because I set up a table that we just sit around a big table and our meals are served and we stay in the one place. It's like going out to dinner with friends. So [there is] conversation of the guy sitting opposite, and the talking is really enhanced. Once the numbers get up, it's a bit more to get through." (Irene, educator). Large classes can leave participants feeling intimidated and teachers frustrated in not being able to reach everyone adequately, thereby compromising their health literacy for birth.

\section{Theme 4: Empowering Participants for Decision-making}

Empowered participants are those with the confidence for decision-making, which is the ultimate goal of health literacy. Many of the participants explained that they considered antenatal educators as gatekeepers of information; however, some identified gaps in information that, if addressed, would have better enabled informed decisions. For example, Claire, as a second-time mother, appeared confident in her knowledge and ability to birth and was empowered further by her personal reading and research regarding birth and parenting to supplement information from the midwife during her antenatal care visits: "I felt refresher- 
wise I was happy to do that via my books and whatnot and I was looking for a less

institutionalized way of birthing as such. So, for me I was trying to avoid words such as pain and contractions and drugs and whatnot." (Claire, participant)

The educators emphasized normal physiological birth to build confidence that would empower he women: "We generally come together with a shared philosophy that birth is a normal physiological process... So,..trying to reinforce that, yeah this is something that women are able to do." (Brooke, educator). Brooke explained that she felt the women came to her classes with a variety of experiences and many had only seen birth as the media portrayed it on television in a dramatic and sensationalized way. Therefore, she used a range of videos of natural birth to help improve women's understanding of the normal process and instill confidence in their ability to birth: "For first time mothers that maybe... have never seen a birth or have maybe quite skewed perceptions of what birth is like from the media and movies and things like that. Sometimes just seeing other ways that women are able to birth can be really positive for them." (Brooke, educator)

Brooke tried to encourage class participants to take ownership of the class and share their stories and experiences with each other, which she described as a partnership approach. She used discussion-based learning, encouraging participants to share stories of their experiences rather than wanting to be considered the expert in charge of classes: “... one of the other values ... is...wanting to get away from 'I'm the expert' and I'm going to give all this knowledge to you. I see it as [a] kind of learning partnership between the woman and myself and often partners are there as well or mothers or support people that often it tends to be a fairly social event [with] a whole lot of discussion-based learning as well, like sharing their stories and experiences." (Brooke, educator)

Clara also recognized that all participants bring experience and knowledge and as an educator, she needs to trust the process of women-led learning: "I thought that women, even 
if it's for their first-time mommies, have so much to offer and so much to teach us as midwives as well. I think midwives learn so much from women that previously I hadn't felt like that, so it's been really, really nice to be able to be confident enough just to trust that women will let you know what they need to know..." (Clara, educator)

Anna, who practiced in combined antenatal care and education, commented that in terms of women learning about pregnancy, birth and parenting: "I think they probably learn the least from us. I think they learn more from all the other women who are there. We are just there to be a bit of a guide really. If someone's saying something that isn 't, or a bit of a myth, then that's not really the right thing. We don't say, that's wrong, we say have you got any other ideas how this might be different? This might work for someone else. It's all about giving the power back to the women and letting them work things out." (Anna, educator)

\section{Being Inclusive of Partners and Significant Others}

Fern enrolled in privately run weekend intensive classes and wanted her partner to attend so that he would understand what was happening and could help her during labor. The classes provided helpful instructions on how her partner could assist while she was in labor and knowledge about what to expect: "My husband came as well and I was keen for him to feel a little bit more comfortable during the labor and have a bit more of an idea about what was going on and how he could help me." (Fern, participant)

Ella's partner could recall information they had been given during the class to provide her with help and support during the early stages of breastfeeding: "I also did a lactation class with them as well, so we did both. Definitely it was worthwhile him coming, because when we were in the thick of it with her, he was able to remember some of the things that I wasn't able to remember, so that was good." (Ella, participant)

\section{Theme 5: Reflections on What is and is not Meaningful and Effective}


Tensions seemed to exist between the information provided by educators and the women's subsequent experience. Meaningful learning refers to the way new knowledge is acquired, related to, and integrated with previous knowledge (Ausubel, 1968). This definition fits well with ANE where educators and participants attend classes with different levels of knowledge and choose what is meaningful for them. Through the process they can apply how it relates to their personal lives and integrate it with the information they already know.

By understanding the characteristics and needs of the class participants a more meaningful learning experience can be achieved. Gina and Claire would have liked further information, especially about parenting topics: "A little, I think I wanted more, well now that I look at it I probably want more." (Gina, participant) and "I think they were very good at providing resources, so the breastfeeding help line, the 13 health, all of those links - all of those lovely links but not actual parenting, no. They...mentioned relationships and focusing on your relationships and that will change but really no relationship coaching as such, which I know is really hard to do in a big group but no, definitely not parenting. " (Claire, participant)

Other participants actively sought the information they required by attending additional classes when their needs were not met by the original antenatal class. "Well I went to a lactation class, so it must have been mentioned, yeah. I was determined to breastfeed...I was trying to get as much information as possible." (Hannah, participant) Dee illustrated information on other standard parenting topics. "They did the standard how to change nappies, how you go about breastfeeding, where you can find help for different problems, support networks and stuff like that that are official. Then we did some exercises in time management where they have a circle, which is your 24 hours, and then they say okay, fill in your naps. Fill in your feeds. Fill in doing the washing. Fill in making dinner - all of 
this kind of stuff - just to give you an idea of how little time you actually have." (Dee, participant)

\section{The Disempowering Effect of Health Facility Policies}

Both antenatal educators and class participants had to balance their needs in teaching and learning with the constraints of institutional policies determined by the health facilities. Many of these constraints were part of the risk management environment of contemporary healthcare organizations. Clara, an experienced antenatal educator, explained how she prepared for each hospital antenatal class by reading the hospital policies to ensure she conformed to hospital expectations: "It was a lot of reading from what the policies were in the hospital to prepare the women for what they would expect their care to be, so for example, if they were birthing in the hospital, my role was to talk to them about what policies are enacted in [the] birth suite and talk to them about what they would be offered ...for example vaginal examinations and how there is quite a tight policy around monitoring their progress in labor. So, to pass that information on we would say that of course it is their choice, but this is what happens, this is how the carers will enact it, if there are any deviations they will increase monitoring in labor, this is when you would be put on a CTG. So, it was all really about preparing them to be birthing in in the hospital system." (Clara, educator). Clara's comments also highlight a potential contradiction for women she sought to empower, and how she supported their preparation for childbirth.

Some class participants perceived that they were being misled by the educator who represented the facility where they were to birth. For example, despite having discussed topics such as noises in labor, Gina found that the reality in labor was that she was expected to suppress her vocalizations to avoid upsetting the hospital midwife: "But honestly the midwife at the hospital was like 'don't scream', I'm like 'I'm trying not to'.” (Gina, 
participant). She would have liked more opportunity to actively practice the vocalizations in class: "I was trying to remember okay keep it calm, keep it low, keep it mooing like a cow as they always say. It's so hard to do, so I think leading up to it, actually vocalizing those sounds more with other women, might actually encourage you to do it when you're actually in the room." (Gina, participant)

Claire would have liked more information regarding hospital policies and the evidence behind them during the antenatal period, specifically about the timing of pushing. This caused tension at a time when she was at her most vulnerable, during labor. Claire reflected on information that may have helped her navigate her childbirth in the hospital: "Probably more on the hospital policies too because I didn't know about things like we only let you push for an hour and a half - well, hang on, why? Until you're there in the moment and you go, hang on, what? And then that starts creating thoughts in the back of your head and things like that. So at least you go in with an awareness that they're probably going to say this at about an hour and a half, maybe it's time for me to advocate for myself and whatnot." (Claire, participant)

\section{Social Networking and Support}

One of the main reasons women in this study attended antenatal classes was to socialize and meet other women who were experiencing the same life event as well as gain support. Claire mentioned the evening supper, and her group antenatal educator encouraged the participants to "bring a plate", giving the participants time to socialize with each other to a greater extent than simply having a coffee or tea break. "So there was an evening tea or supper so we all had to bring a plate as well and then we had a break halfway through and it was for about 20 minutes so that was - if you have any social skills you could socialize." (Claire, participant) 
The postnatal reunion was very popular with the women in this study, but only some antenatal classes offered a reunion, because of the expense involved: "Unfortunately, funding doesn't allow us to attend on a paid day. If the educator feels that she would like to do a reunion for those couples, and attend, she can, but she does it in her own time. But we also set up a contact list, and the most predominant person in the class is often the one that takes that list with everyone's permission and organizes the catch-up themselves afterwards." (Helen, educator), and "I think the groups have definitely shown that that's a strength. Your testament to that is the group's still meeting two years from when we first started. I would say most of the groups that have gone through here are actually still meeting together." (Dawn, educator)

\section{DISCUSSION}

Study findings revealed the key factors that influenced ANE and perceptions of educators and those attending the education on the extent to which the structures and processes promoted health literacy. Educators discussed the need for women to be empowered for decisionmaking, to make choices as a partner in their care. Clearly, they were cognizant of the link between consumer and family participation, better quality of care and positive outcomes, which has been well documented professionally, including Legare et al.'s (2012) systematic review of the literature. For these women, however, restrictions on choice were imposed by the healthcare system when they presented for birth; a similar finding as other studies on childbirth experiences (Kabakian-Khasholian \& Portela, 2017; Cook \& Loomis, 2012).

The current findings underlined the importance of peer learning as a form of participation, (Petersson, Petersson \& Hakansson, 2004; Svensson, Barclay \& Cooke, 2006; Nolan, 2009). Petersson et al., (2004) found that women needed to seek information from other parents with similar experiences, not just the 'experts'. The challenge for antenatal educators in facilitating peer learning is to balance their agenda for sharing professional 
information with the understanding that consumers such as pregnant women and their families have unprecedented awareness of health issues, despite some of this information being contestable. Lima-Pereira et al. (2012) argue that the Internet should be used strategically to reinforce content covered in class, thereby improving participants' understanding and interactive health literacy. In Australia, national and state governments have invested in health information websites (Hill \& Sofra, 2018) which more recently have actively sought and incorporated consumer contributions. These initiatives are aimed at meeting the Australian Commission on Safety and Quality in Health Care (ACSQHC) service standard 2: Partnering with Consumers to promote health literacy. Many digital initiatives are currently available including online ANE classes; however, class participants with sound literacy skills may still find that understanding healthcare information is challenging (Carolan, 2007a, 2007b). Understanding medical vocabulary, navigation of the healthcare system (Cornett, 2009) and/or identification of websites with high quality, evidence-based and unbiased information can pose challenges for ANE participants. These elements are also integral to health literacy.

The overarching goal of health literacy is particularly relevant during pregnancy, birth and throughout parenthood, and would be more readily achieved by having a consistent approach to ANE. Skills in facilitation, rather than a more didactic approach of conveying information provided by the institution, should be part of the educational preparation for antenatal educators, especially as facilitated discussion is preferred by participants (Andersson, Christensson \& Hildingsson, 2012; Wiener \& Rogers 2008). Nutbeam (2000) proposes that transmitting educational information in a clinical setting often fails to consider the social or educational circumstances of the participants. Enabling participants to take the lead and direct their own learning through a facilitative style of teaching can help overcome barriers to effective engagement and learning. Discussions can be rich and meaningful when 
they focus on the participants' specific learning needs and facilitate skill development at a level of interactive health literacy. In this study, the inclusion of a topic such as conception for already expectant parents indicated a static program design as well as a lack of input from class participants or response to prior evaluations.

Participants may not be fully prepared for birth and parenthood if they have little understanding or opportunities to discuss and apply information provided in class, which would help develop sufficient health literacy for decision-making (Nutbeam, 2000). ANE that facilitates social support for class participants also contributes to interactive health literacy as it helps participants to develop skills in a supportive, peer environment (Nutbeam, 2000). A more facilitative approach offers the opportunity to move current practice and thinking about ANE away from a simple transfer of knowledge, such as in functional health literacy, towards a more active process of empowering women and helping them develop critical health literacy. For example, the use of group-based ANE such as the CenteringPregnancy ${ }^{\mathrm{TM}}$ model has been shown to improve participant satisfaction (Hildingsson, Dalen, Sarenfelt, \& RansjoArvidson, 2013; Homer, Ryan, Leap, Foureur, \& Teate, 2012).

In applying information that makes learning meaningful to participants, Bainbridge (2009) posed an interesting question; that is, whether anything could prepare women for childbirth, given that every person was unique, and each pregnancy journey would be different. This is interesting in that even class participants with good health literacy skills may face challenges in interpreting information provided by particular educators (Nolan, 2009; Fredriksen, Harris \& Moland 2016). Being confused or having conflicting ideas can cause them unnecessary anxiety and tension during their pregnancy. Several class participants in this study experienced anxiety when they were provided with a large amount of information, over a short period. To overcome this problem some chose to take notes for consideration at a later time. 
Antenatal educators are required to be not only innovative and resourceful in how they provide education to help develop personal empowerment of class participants, but they are also required to incorporate and synthesize evidence into their practice (Thielen, 2012). In addition, they play an important role in promoting confidence in class participants, to allay childbirth fears through appropriate use of context and content (Downer 2019). Through formal education and informal personal experiences these skills can be developed. When empowering participants to make decisions, several antenatal educators in this study encouraged participants to discuss topics amongst each other and draw their own conclusions as applied to their individual situation and values. Symon and colleagues (2017) found that one of the main drivers of contemporary antenatal care/education is to empower women. In this study those women who attended privately run classes were provided with more information and skills to challenge the health care facility in which they were going to birth.

This approach to facilitating health literacy is a useful way to assist those attending ANE to develop the capacity and confidence to make informed decisions regarding their care. According to Shieh and Halstead (2009) and Lori (2017) a further level of health literacy has the potential to influence how women seek information to not only improve their health knowledge but also develop self-advocacy skills. At a time when models of midwifery practice have entrenched the idea of woman and family participation and empowerment, ANE has remained more provider than consumer focused.

\section{Strengths, Limitations and Recommendations for Further Research}

The contribution that this study makes to the literature on ANE provision for expectant parents needs to be considered in context. A study strength is that not only midwives were interviewed, but doulas who had trained as antenatal educators; an alternative dimension as yet unexplored. Both primiparous and multiparas' women were recruited. Therefore, a broad range of experiences were discussed, from those women who opted to have an independent 
midwife and homebirth to those who had limited alternative options and were birthing in the only health care facility available for them. Interpretive Description was a useful research approach in that the researcher was an antenatal educator who was familiar with the topic, which in Hunt's (2009) view would be seen as a strength of the study, due to the recognition of disciplinary biases and how they impact the study. Finally, by using the three aspects of Nutbeam's (2000) health literacy as a conceptual framework and a basis to situate the findings, this study has established a clear goal for ANE in terms of achievement of health literacy which could be considered to be a unifying concept for all programs.

Study limitations include the small sample size, restricted participant demographic information collected, and the limited generalizability of the findings. The use of snowball sampling for recruitment may have increased the chance that both class participants and antenatal educators with similar views were interviewed, despite not necessarily practicing under the guidelines of the same state or health service. Nevertheless, this was balanced by educators and class participants being recruited from two Australian states: Queensland and Victoria, which are two very different states in terms of models of ANE, geography including distance from health care facilities, and the organization of health services.

The findings suggest recommendations for further studies to explore a range of influences on promoting health literacy for maternal and family antenatal, birthing and postnatal care. These include in-depth examination of models of care that include the woman and family voice in improving ANE; the extent to which ANE is provided from a base of research evidence; studies that compare quality and safety outcomes in woman/family oriented ANE and those that remain grounded in hospital and health system expectations; research into long-term participation in health decision-making as a result of empowerment in ANE; and comparative cross-cultural studies of models of ANE and their health literacy outcomes. 


\section{CONCLUSION}

ANE is firmly embedded within our culture as a way of preparing for pregnancy, childbirth and parenting. This study has revealed contemporary insights into current practice in ANE from the perspective of both antenatal educators and the class participants. These key insights regarding the role of the antenatal educator, include that antenatal educators should be responsive to participant needs for the stage they are at in pregnancy. They have an important opportunity to promote confidence and allay childbirth fears through appropriate use of context and content. The birthing institution's requirements should be considered secondary to the primary purpose of ANE, which is to provide a meaningful experience that meets expectations in the preparation of women and their families for birth and the early postnatal period. Examining the influences on women and their partners developing health literacy in relation to birth and parenting was the overarching purpose of this study. These study findings have implications for maternity care settings aiming to provide woman-and family centered care in their future ANE strategies and policies. 


\section{REFERENCES}

Andersson, E, Christensson, K, \& Hildingsson, I. (2012). Parents' experiences and perceptions of group-based antenatal care in four clinics in Sweden. Midwifery. 28(4), 502-508. https://doi: 10.1016/j.midw.2011.07.006.

Australian Commission on Safety and Quality in Health Care (ACSQHC). (2014). National Safety and Quality Health Service Standard 2: Partnering with Consumers - Embedding partnerships in health care. Sydney. Retrieved from: https://www.safetyandquality. gov.au/standards/nsqhs-standards

Ausubel, D. P. (1968). Educational Psychology: A Cognitive View. Holt, Rinehart and Winston, New York.

Bainbridge, J. (2009). Equal access to high-quality antenatal classes. Brit J of Midwifery. 17(7):457-457. https://doi.org/10.12968/bjom.2009.17.7.43063

Barimani, M., Forslund Frykedal, K., Rosander, M., \& Berlin, A. (2018). Childbirth and parenting preparation in antenatal classes. Midwifery. 57:1-7. https://doi.org/10.1016/j. midw.2017.10.021

Bergin, M. (2010). NVivo 8 and consistency in data analysis: reflecting on the use of a qualitative data analysis program. Nurse Researcher. 18(3), 6-12. https://doi: $10.7748 / \mathrm{nr} 2011.04 .18 .3 .6 . c 8457$

Berkman, N.D. (2011). Low health literacy and health outcomes: an updated systematic review. Ann Intern Med. 155:97-107. https://doi: 10.7326/0003-4819-155-2-20110719000005.

Carolan, M. (2007a). Health literacy and the information needs and dilemmas of first-time mothers over 35 years. J Clin Nurs. 16(6),1162-1172. https://doi.org/10.1111/j.13652702.2007.01600.x 
Carolan, M. (2007b). The project: having a baby over 35 years. Women and Birth. 20(3), 121-126. https://doi.org/10.1016/j.wombi.2007.05.004

Cook, K., \& Loomis, C. (2012). The impact of choice and control on women's childbirth experiences. $J$ Perinat Educ. 21(3):158-168. https://doi.org/10.1891\%2F10581243.21.3.158

Cornett, S. (2009). Assessing and addressing health literacy. Online J of Iss in Nurs. 14(3), 2. https://doi.10.3912/OJIN.Vol14No03Man02

Downer, T. (2019). Exploring Antenatal Education: An Interpretive Description. (Unpublished doctoral dissertation). University of the Sunshine Coast, Australia.

Fredriksen, E.H., Harris, J., \& Moland, K.M. (2016). Web-based discussion forums on pregnancy complaints and maternal health literacy in Norway: a qualitative study. $J M e d$ Internet Res. 18(5); e113. https://doi.10.2196/jmir.5270

Hildingsson, I., Dalen, K., Sarenfelt, L., \& Ransjo-Arvidson, A.B. (2013). First-Time Parents' Perception of Antenatal Education in Sweden. International Journal of Childbirth. 3(1), 28-38. https://doi.10.1891/2156-5287.3.1.28

Hill, S.J., \& Sofra, T.A. (2018). How could health information be improved? Recommended actions from the Victorian Consultation on Health Literacy. Aust Health Rev. 42(2),134139. https://doi: 10.1071/AH16106.

Homer, C., Ryan, C., Leap, N., Foureur, M., \& Teate, A. (2012). Group versus conventional antenatal care for women. Cochrane Database System Reviews, 11, CD007622. https://doi: 10.1002/14651858.CD007622.pub3.

Hunt, M. (2009). Strengths and challenges in the use of interpretive description: reflections arising from a study of the moral experience of health professionals in humanitarian work. Qualitative Health Research. 19(9),1284-1292. https://doi: 10.1177/ 1049732309344612. 
Kabakian-Khasholian, T., \& Portela, A. (2017). Companion of choice at birth: factors affecting implementation. BMC Pregnancy Childbirth. 17:265. https://doi.org/10.1186/ s12884-017 -1447-9.

Leare, F., Turcotte, D., Stacey, D., Katte, S., Kryworuchko, J., Graham, I.D. (2012). Patients' perceptions of sharing in decisions. The Patient-Patient-Centered Outcomes Research. 5 (1), 1-19.

Lima Pereira, P., Bermu'dez-Tamayo, C., \& Jasienska, G. (2012). Use of the Internet as a source of health information amongst participants of antenatal classes. J Clin Nurs. 21:322-330. https://doi: 10.1111/j.1365-2702.2011.03910.x

Lori, J., Ofos-Darkwah, H., Boyd, C., Banerjee, T., Adanu, R.M.K. (2017). Improving health literacy through group antenatal care: a prospective cohort study. BMC Pregnancy Childbirth. 17(1), 228. https://doi.10.1186/s12884-017-1414-5

Morse, J. (1994). Emerging from the data: the cognitive processes of analysis in qualitative inquiry. in J Morse (ed.). Critical issues in qualitative research methods. Sage. Thousand Oaks. CA. p. 23-43.

Nijman, J., Hendriks, M., Brabers, A., de Jong, J., \& Rademakers, J. (2014). Patient activation and health literacy as predictors of health information use in a general sample of Dutch health care consumers. J Health Commun. 19(8), 955-969. https://doi:10.1080/10810730.2013.837561.

Nolan, M. (2009). Information giving and education in pregnancy: a review of qualitative studies. J Peri Educ. 18(4), 21-30. https://doi:10.1624/105812409X474681

Nutbeam, D. (2000). Health literacy as a public health goal: a challenge for contemporary health education and communication strategies into the $21^{\text {st }}$ century. Health Promotion International. 15(3), 259-269. https://doi.org/10.1093/heapro/15.3.259 
Petersson, K., Petersson, C., \& Hakansson, A. (2004). What is good parental education? Interviews with parents who have attended parental education sessions. Scand J Caring Sci. 18(1), 82-89. https://doi.10.1111/j.1471-6712.2004.00260.x

Renkert, S., \& Nutbeam, D. (2001). Opportunities to improve maternal health literacy through antenatal education: an exploratory study. Health Promo Int. 16(4), 381-388. https://doi.10.1093/heapro/16.4.381

Shieh, C., \& Halstead, J.A. (2009). Understanding the impact of health literacy on women's health. J Obstet Gynecol Neonatal Nurs. 38(5), 601-612. https://doi.10.1111/j.15526909.2009.01059.x

Svensson, J., Barclay, L., \& Cooke, M. (2006). Randomised-controlled trial of two antenatal education programmes. Midwifery. 25(2), 114-125. https://doi.org/10.1016/j.midw.2006. 12.012

Symon, A., Pringle, J., Downe, S., Hundley, V., Lee, E., Lynn, F., McFadden, A., McNeill, J., Renfrew, M., Ross-Davie, M., van Teijlingen, E., Whitford, H., \& Alderdice, F. (2017). Antenatal care trial interventions: a systematic scoping review and taxonomy development of care models. BMC Pregnancy and Childbirth. 17, 8. https://doi.org/10.1186/s12884-016-1186-3

Thielen, K. (2012). Exploring the group prenatal care model: a critical review of the literature. J of Peri Educ. 21(4), 209-218. https://doi.10.1891/1058-1243.21.4.209 Thorne, S. (2016). Interpretive description. 2e. Left Coast Press. Walnut Creek. USA. Wiener, A., \& Rogers, C. (2008). Antenatal classes: women can't think beyond labour. Brit $J$ of Midwifery. 16(2), 121-124. https://doi.org/10.12968/bjom.2008.16.2.28343

World Health Organization. (2016). The Shanghai Declaration on promoting health in the 2030 Agenda for Sustainable Development. Geneva. Retrieved from: http://www.who.int/healthpromotion/conferences/9gchp/shanghai-declaration.pdf?ua=1 